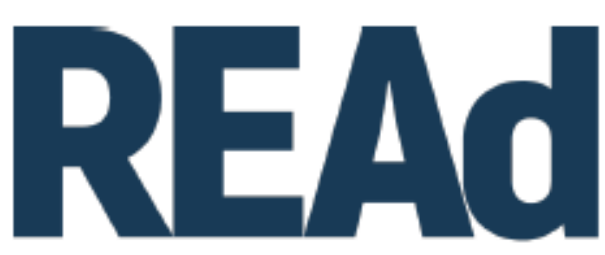

Revista Eletrônica de Administração

\title{
EFEITOS DA SATISFAÇÃO, CONFIANÇA E SEUS ANTECEDENTES NA INTENÇÃO DE RECOMPRA ONLINE ${ }^{1}$
}

\author{
Luiz Eduardo Couri Boueri² \\ Jorge Brantes Ferreira ${ }^{3}$ \\ Roberto Pessoa de Queiroz Falcão ${ }^{4}$
}

http://dx.doi.org/10.1590/1413-2311.315.104396

\begin{abstract}
RESUMO
O presente estudo buscou analisar os efeitos da satisfação, confiança e seus antecedentes na intenção de recompra online. A partir da teoria, são formuladas hipóteses dos construtos em relação à intenção de consumidores em recomprar online. As hipóteses foram testadas por meio de uma survey, a qual resultou em uma amostra de 250 indivíduos, cujo único requisito era já ter realizado compras online. Os dados coletados foram analisados via modelagem de equações estruturais, com a verificação de efeitos significativos em várias das hipóteses do estudo, tendo destaque para a confiança do consumidor, atuando como mediadora da relação entre os demais construtos e a intenção de recompra online. Cinco das nove hipóteses propostas se confirmaram, incluindo as relações entre: facilidade de uso e controle percebido, controle percebido sobre confiança, satisfação sobre confiança, benefícios percebidos sobre satisfação, e da confiança sobre intenção de recompra online.
\end{abstract}

Palavras-chave: Comportamento de consumo. Satisfação. Confiança. Intenção de recompra online.

\section{EFFECTS OF SATISFACTION, TRUST AND THEIR ANTECEDENTS ON ONLINE REPURCHASE INTENTION}

\footnotetext{
${ }^{1}$ Recebido em 17/6/2020, aceito em 24/2/2021.

${ }^{2}$ Pontifícia Universidade Católica do Rio de Janeiro - Departamento de Administração; Rio de Janeiro (RJ) Brasil; http://orcid.org/0000-0002-3410-9034; luizcboueri@gmail.com.

${ }^{3}$ Pontifícia Universidade Católica do Rio de Janeiro - Departamento de Administração; Rio de Janeiro (RJ) Brasil; http://orcid.org/0000-0002-9579-4477; jorgebf@gmail.com.

${ }^{4}$ Universidade Unigranrio - Programa de Pós-Graduação em Administração; Duque de Caxias (RJ) - Brasil; http://orcid.org/0000-0002-8125-0938; robertopqfalcao@gmail.com. 
The present study sought to analyze the effects of satisfaction, trust and their antecedents on online repurchase intention. Based on extant theory, a model was proposed to evaluate the effects of several relevant constructs on consumers' intention to repurchase online. The model's hypotheses were tested through a survey that resulted in a sample of 250 individuals, all of whom had made online purchases in the past. The collected data were analyzed using structural equation modeling, with the verification of significant effects in several of the study's hypotheses, with trust acting as a mediator between the other constructs and the intention to repurchase online. Five out of the nine of the proposed hypotheses were confirmed, namely the relationships between ease of use and perceived control, perceived control and trust, satisfaction and trust, perceived benefits and satisfaction, and trust and online repurchase intention.

Keywords: Consumer behavior. Satisfaction. Trust. Online repurchase intention.

\section{EFECTOS DE LA SATISFACCIÓN, LA CONFIANZA Y SUS ANTECEDENTES SOBRE LA INTENCIÓN DE VOLVER A COMPRAR EN LÍNEA}

El presente estudio buscó analizar los efectos de la satisfacción, la confianza y sus antecedentes en la intención de recompra en línea. Basado en la teoría, se propuso un modelo para evaluar los efectos de varias construcciones relevantes sobre la intención de los consumidores de recomprar en línea. Las hipótesis del modelo se probaron a través de una encuesta que resultó en una muestra de 250 individuos, todos los cuales habían realizado compras en línea en el pasado. Los datos recopilados se analizaron utilizando modelos de ecuaciones estructurales, con la verificación de efectos significativos en varias de las hipótesis del estudio, con la confianza actuando como mediador entre las otras construcciones y la intención de recomprar en línea. Se confirmaron cinco de las nueve hipótesis propuestas, a saber, las relaciones entre la facilidad de uso y el control percibido, el control percibido y la confianza, la satisfacción y la confianza, los beneficios percibidos y la satisfacción, y la confianza y la intención de recompra en línea.

Palabras clave: Comportamiento del consumidor. Satisfacción. Confianza. Recompra en línea

\section{INTRODUÇÃO}

O crescimento do varejo eletrônico nos últimos anos tem sido expressivo, sobretudo com o advento do uso de smartphones e com o aumento da velocidade de conexão, fazendo com que os consumidores se sintam cada vez mais seguros e confortáveis em suas transações de comércio eletrônico. Segundo estimativas do The eMarketer (2019a), o faturamento mundial do comércio online atingiu US\$25,038 trilhões em 2019 (incremento de 4,5\% sobre 2018). A projeção é que em 2023, o comércio eletrônico atinja a cifra de US\$29,763 trilhões, segundo o mesmo levantamento, tendo a América Latina crescido 21,3\%, chegando à cifra de US\$71,34 
bilhões em vendas (THE EMARKETER, 2019b). Ainda segundo The eMarketer (2019b), o Brasil é o maior mercado de $m$-commerce da região, representando $34,0 \%$ de todas as vendas. Já o relatório Webshoppers da E-bit, aponta para um faturamento do e-commerce no Brasil de R \$133 bilhões em 2018 (EBIT NIELSEN, 2019), mesmo diante do cenário de desaceleração econômica, sendo as redes sociais o segundo maior motivador de compras, perdendo apenas para os websites de busca. O número de internautas no Brasil também tem crescido apesar do baixo crescimento da economia, tendo atingido 149 milhões, aproximadamente $70 \%$ dos 211 milhões de habitantes (PAGBRASIL, 2019), sendo que 85\% dos usuários de Internet no Brasil navegam na web todos os dias, e permanecem um total de $9 \mathrm{~h}$ e 29 min por dia na Internet, bem acima da média global de 6 h e $42 \mathrm{~min}$.

Mais de 50\% das vendas de comércio eletrônico em 2019, que representam US\$1,7 trilhão foram provenientes dos e-marketplaces (WEBRETAILER, 2020), que conectam compradores e vendedores por meio de uma plataforma de integração, fornecidas por sites de compras com alto volume de acessos (HONG; $\mathrm{CHO}, 2011)$. Os principais e-marketplaces são Amazon e eBay (globalmente), Mercado Libre (América do Sul) e Americanas (Brasil), de acordo com Webretailer (2020). Dentre os possíveis motivos para grandes empresas de comércio eletrônico adotarem o e-marketplaces como estratégia de negócios estão o aumento da capacidade de vendas; a redução de custos e perdas de estoque; aceleração do fluxo de caixa; maior alcance de entrega; redução do tempo logístico (BERNAL; JIMENEZ-BARROS; MOLINARES; PATERNINA-ARBOLEDA, 2019).

Assim, dada a relevância do e-commerce no país e sua acirrada concorrência, estimular a fidelização de clientes tornou-se um objetivo crucial para as empresas do segmento, tendo em vista que a obtenção de novos clientes custa mais tempo e esforço do que a manutenção dos já existentes (ZHANG; FANG; WEI; RAMSEY; MCCOLE; CHEN, 2011; CHOU; HSU, 2016).

A intenção de recompra online é um fator chave de sucesso para o varejista online (CHOU; HSU, 2016; FANG et al., 2014), sendo ela uma manifestação da lealdade do consumidor (ZBOJA; VOORHEES, 2006; ZHANG et al., 2011). No entanto, fazer com que o cliente permaneça leal à determinada empresa é uma tarefa desafiadora no ambiente online, quando comparado ao varejo físico. Isso se deve pela facilidade de comparação de preços que a Internet oferece, por meio de websites específicos para tal função, além dos baixos custos de mudança para o consumidor (CHOU; HSU, 2016). Sendo assim, descobrir quais fatores, e como estes afetam a intenção de recompra do consumidor passa a ter um papel fundamental para o sucesso dos comerciantes online. 
Diante deste contexto, este trabalho se propôs investigar a influência de elementos do varejo online sobre a intenção de recompra online dos consumidores. O estudo visa investigar a interação entre a satisfação, a confiança e outros antecedentes no contexto de compras repetidas em websites da Internet. Busca-se alcançar uma melhor compreensão sobre os fatores que influenciam a intenção de recompra online, propondo-se entender se a satisfação e a confiança do consumidor afetam a sua intenção de recompra, assim como se o controle e benefícios percebidos pelo consumidor ao navegar no website do varejista afetam a sua confiança e sua satisfação. Portanto, é proposto um modelo que associa os componentes supracitados em busca da explicação da variável dependente (intenção de recompra online), integrando a (i) satisfação dos consumidores com base em suas transações reais e intenção de recompra (PEE; JIANG; KLEIN, 2018); a (ii) customização dos serviços como desvantagem de um maior risco percebido (DING; KEH, 2016), diferenciando-se os consumidores (com foco hedônico), que preferem serviços personalizados, dos que preferem serviços padronizados (com foco utilitário); a (iii) relação entre a conectividade e às aplicações (apps) online (ver HUBERT; BLUT; BROCK; BACKHAUS; EBERHARDT, 2017); (iv) os sentimentos de controle gerando mais satisfação e confiança (GENTILE; SPILLER; NOCI, 2007; KOUFARIS; AJIT KAMBIL, 2011). No modelo também é testada a conveniência, que se tornou ainda mais relevante com o advento dos smartphones e tablets (RODRÍGUEZ-TORRICO; SAN-MARTÍN; SAN JOSÉCABEZUDO, 2019). O estudo apresenta implicações gerenciais, úteis para varejistas online, como a importância da clareza das informações, atenção aos detalhes de navegação em websites de e-commerce, mostrando-se importante monitorar as percepções da facilidade de uso do website e de sua satisfação do consumidor visando a intenção de recompra online.

\section{REFERENCIAL TEÓRICO}

\subsection{INTENÇÃO DE RECOMPRA ONLINE E LEALDADE}

A intenção de recompra é definida por alguns autores como sendo a decisão do cliente de se envolver em atividades futuras de compra, quer seja relativa a um produto ou serviço, sendo associada também a experiências de compra online repetidas (HUME; MORT; WINZAR, 2007). O tema é muito pesquisado, sendo que recentemente destacam-se alguns trabalhos que evidenciaram a intenção de recompra aplicada a diferentes contextos e construtos, incluindo a influência do boca-boca digital, de características do website, da lealdade e percepção de marcas na recompra, e a recompra no ambiente de turismo (VALLEJO; 
REDONDO; ACERETE, 2016; CHINOMONA; MAZIRIRI, 2017; PEE; JIANG; KLEIN, 2018; LIANG; CHOI; JOPPE, 2018).

A intenção de recompra é uma manifestação da lealdade do consumidor (ZBOJA; VOORHEES, 2006; ZHANG et al., 2011). Segundo a definição de Dick e Basu (1994) "a lealdade do cliente é vista como sendo a força da relação entre atitude relativa de um sujeito e seu comportamento de compra repetido". No entanto, ao se comparar o ambiente de compras off-line ao varejo online, é mais difícil haver lealdade nas compras online, devido à alguns fatores. Por exemplo, há baixos custos de mudança para o consumidor, dado que não há necessidade de gastar tempo e recursos para ir até outra loja, além da facilidade de comparação de preços nos buscadores (CHOU; HSU, 2016). Os custos de mudança percebidos e o desenvolvimento de uma comunidade online exercem também impacto sobre as intenções de recompra, evidenciando uma influência social sobre a retenção de clientes (TSAI; HUANG; JAW; CHEN, 2006; TOUFAILY; RICARD; PERRIEN, 2012; VALLEJO; REDONDO; ACERETE, 2016)

É interessante também relatar os achados de Wen, Prybutok e Xu (2011), corroborados por Ashraf, Thongpapanl e Spyropoulou (2016), os quais atestam que tanto fatores utilitários (facilidade de uso e utilidade percebida), fatores hedônicos (prazer percebido) quanto fatores sociais/psicológicos (confirmação, satisfação e confiança) influenciam na intenção de recompra online. Embora sua modelagem sugira que tanto os fatores utilitários quanto os fatores hedônicos forneçam explicações estatisticamente significativas da variação na intenção de recompra online dos consumidores, na fase pós-compra, os fatores utilitários desempenham um papel mais importante do que os fatores hedônicos. Ainda, de acordo com os estudos de Hsu, Chang, Chu e Lee, (2014), no caso das compras coletivas, evidências apontam para um aumento na intenção de recompra derivado da satisfação e aumento da qualidade percebida. Os autores também evidenciam que a confiança aumenta tanto a satisfação dos clientes quanto a qualidade percebida nas transações, o que mostra a importância da construção de uma reputação online para influenciar a confiança dos clientes.

Devido às grandes diferenças entre os ambientes de varejo online e off-line, Chiu, Hsu, Lai e Chang (2012) afirmam não ser possível aplicar diretamente no ambiente online o conhecimento sobre lealdade e retenção dos consumidores já profundamente estudado no ambiente off-line. Conforme afirmam Gupta e Kim (2007), a incapacidade dos varejistas online em gerenciar as mudanças de expectativas dos clientes faz com que mais de 50\% dos clientes que retornam raramente concluam uma terceira compra. Em seu modelo são evidenciados os efeitos da conveniência percebida e da mudança de preço percebida sobre a experiência da 
compra. Já os efeitos de valor percebido e do prazer não tem significância. Um outro fator apontado por Park, Bhatnagar e Rao (2010) é a importância dos selos de garantia de terceiros, que mitigam os receios dos clientes, tendo impacto positivo na satisfação do cliente online e na intenção de recompra, o que parece ter efeito similar à validação pelo boca-a-boca de terceiros (TOUFAILY; RICARD; PERRIEN, 2012; VALLEJO; REDONDO; ACERETE, 2016).

A lealdade do consumidor considera aspectos atitudinais e comportamentais. Primeiramente, a abordagem atitudinal refere-se ao estado de espírito do cliente (PEPPERS; ROGERS, 2016). Por essa definição, o consumidor é leal a determinada marca ou empresa quando possui uma atitude positiva e preferencial em relação a ela, gostando da empresa, de seus produtos, seus serviços ou marcas, e, portanto, preferindo comprar a partir dela, ao invés de adquirir produtos de seus concorrentes. Em termos puramente econômicos, a definição de lealdade pela abordagem atitudinal do cliente significaria estar disposto a pagar um prêmio para uma marca detrimento de outra, mesmo quando os produtos que elas representam são praticamente equivalentes (PEPPERS; ROGERS, 2016). A ênfase nesse caso está na intenção e não no comportamento efetivo, seguindo o paradigma seminal da desconfirmação (OLIVER, 1980), que tem sido amplamente aplicado na pesquisa de comércio eletrônico e sistemas de informação (HOSSAIN; QUADDUS, 2012; KALIA, 2018; QAZI; TAMJIDYAMCHOLO; RAJ; HARDAKER; STANDING, 2017).

Já na abordagem comportamental, a lealdade depende da conduta real de um cliente, independentemente das atitudes ou preferências que estão por trás desse comportamento. Por esta definição, um cliente deve ser considerado fiel a uma empresa simplesmente por comprar frequentemente com ela. A lealdade comportamental está preocupada com a atividade recompra, ao invés de atitudes ou preferências. Assim, é teoricamente possível para um cliente ser leal a uma marca, mesmo não gostando da mesma, desde que haja outras razões para repetir a compra (YI; LA, 2004; PEPPERS; ROGERS, 2016).

Ressalta-se ainda, que a intenção de recompra é um fator chave de sucesso para o varejista online (FANG et al., 2014; CHOU; HSU, 2016), pois pode gerar incremento em sua lucratividade e frequência de visitas ao website, aumento de share of wallet (participação de produtos e/ou serviços de determinada empresa no orçamento do consumidor), busca menor por alternativas, maior disposição a pagar mais, aumento de boca-a-boca positivo, aumento da retenção e satisfação geral com a experiência (TOUFAILY; RICARD; PERRIEN, 2012). Além disso, a obtenção de novos clientes pode ser mais custosa e demandar maior esforço do que a manutenção dos já existentes (ZHANG et al., 2011; CHOU; HSU, 2016). Por isso, a retenção de consumidores possui um papel fundamental no sucesso de um varejista eletrônico (FANG 
et al., 2014; CHOU; HSU, 2016). Assim sendo, os consumidores retidos são vistos como um ganho de vantagem competitiva, dado a menor sensibilidade desses clientes a mudanças de preços e a maior possibilidade de recomendarem a empresa para novos consumidores (ZBOJA; VOORHEES, 2006; ZHANG et al., 2011).

No presente estudo foi investigada a intenção de recompra do consumidor, pois entendese que ela é pré-existente quando um consumidor escolhe determinado website para adquirir um produto e/ou serviço. A literatura aponta para muitos fatores relacionados ao processo de decisão de compras pela Internet, apresentados a seguir, dando suporte aos construtos que compõem o modelo sugerido por esta pesquisa.

\subsection{ANTECEDENTES DA CONFIANÇA NO COMPORTAMENTO DO CONSUMIDOR ON-LINE}

A atitude dos consumidores em relação a compras pela Internet depende primeiramente de características relevantes dos websites de compra online (MONSUWÉ; DELLAERT; DE RUYTER, 2004; ROSE; CLARK; SAMOUEL; HAIR, 2012). Essas características podem ser tanto relativas às dimensões funcionais e utilitárias, quanto às emocionais e hedônicas (MONSUWÉ et al., 2004). Satisfação e confiança são construtos muito utilizados em estudos sobre a intenção de recompra no contexto do comportamento do consumidor online (CHIU et al., 2012; KIM; GALLIERS; SHIN; RYOO; KIM, 2012), embora sejam reconhecidas como multidimensionais. Apesar de diversos estudos terem utilizado a satisfação ou confiança, apenas um número limitado deles examinou as relações entre confiança, satisfação e intenção de recompra, sendo que a maioria considerou a satisfação de uma forma geral. No entanto, nesse caso, seria ideal medir separadamente a satisfação baseada na experiência das transações online, uma vez que os consumidores podem considerar diferentes fatores ao avaliar seu nível de satisfação durante sua experiência (HUANG; DUBINSKY, 2014).

No presente estudo, são examinados cinco antecedentes da satisfação e da confiança do consumidor: facilidade de uso, customização, conectividade, controle percebido e benefícios percebidos. Conforme aponta o estudo de Rose et al. (2012), a variável controle percebido terá um efeito mediador sobre três variáveis: facilidade de uso, customização e conectividade. No decorrer dessa seção serão apresentadas as hipóteses envolvendo as relações entre os construtos. O construto facilidade de uso percebida é muito utilizado nos modelos de aceitação tecnológica, tendo surgido nos estudos seminais de Davis (1989), e incorporado mais tarde em estudos de e-commerce (por exemplo de GEFEN; STRAUB, 2000). A percepção de facilidade de uso é a 
avaliação de um indivíduo de que a interação com a tecnologia será relativamente livre de dificuldades (AGARWAL; KARAHANNA, 2000). Já Chiu, Chang, Cheng e Fang (2009) definem a facilidade de uso como a percepção de facilidade percebida pelo consumidor ao utilizar o website de compras.

Segundo Cheung, Chan e Limayem (2005), a facilidade de uso de websites de $e$ commerce, envolve a navegação, buscas e suas funcionalidades, o que afeta diretamente a experiência do consumidor e, por conseguinte, sua satisfação e confiança nas compras online. Elliott e Speck (2005), por sua vez, apontam para o fato de que a facilidade de uso inclui fatores como visualização em tela, clareza na organização do sistema, apresentação da informação em um sentido lógico, facilidade de navegar, design da página e facilidade para encontrar as informações. Já Pearson, Pearson e Green (2007) destacam que, pelo fato da Internet ser um ambiente aberto, usuários de diversos níveis de habilidade navegam em websites que exigem por sua vez diferentes níveis de conhecimento. Sendo assim, a facilidade de uso pode ser um fato motivador para um usuário escolher navegar em determinado website em detrimento de outro. Mais recentemente, diversos trabalhos têm utilizado esse construto em seus modelos (a exemplo de ASHRAF; THONGPAPANL; SPYROPOULOU, 2016; OZTURK; BILGIHAN, NUSAIR; OKUMUS, 2016; ELKASEH; WONG; FUNG, 2016).

Indagações relativas à cognição pertinente à forma de avaliar a satisfação, fazem com que se busque investigar se haveriam maneiras diferentes de percebê-la durante a transação online ao ser comparada com o processo de experiência. Nesse sentido, faz-se também crucial investigar se a satisfação baseada em transações afeta a satisfação dos consumidores, com base na experiência real e na intenção de recompra. Segundo Pee, Jiang e Klein (2018), essas questões permanecem incertas na literatura de comportamento do consumidor on-line. Por exemplo, Kim, Kim e Kim (2009) estudaram confiança e satisfação para prever a intenção de recompra nos períodos de pré-compra, durante transações de compra e pós-compra, embora não tenham identificado como se daria o processo de transação e experiência, sendo que a maioria dos estudos estipulava que os clientes mudariam para outro fornecedor de produtos ou serviços com base no julgamento de sua satisfação durante o processo de compra (KIM; OK; CANTER, 2010; ZHANG et al., 2011). Há também estudos recentes da literatura nacional relativos à confiança do e-commerce e recompra (DELIBERALI; BRANDÃO; BIZARRIAS, 2019, AUGUSTO; SANTOS; ESPÍRITO SANTO, 2020).

Portanto, dado que a facilidade de uso, como o próprio nome já diz, é medida pelo nível de esforço percebido pelo cliente ao navegar por determinado website, quanto maior a facilidade do cliente para aprender a navegar pelo website do varejista e comprar aquilo que deseja, maior 
será o seu nível de controle percebido, melhorando, por conseguinte sua experiência (GEFEN, 2003; ROSE et al., 2012). Dessa maneira, propõe-se a seguinte hipótese:

H1: A facilidade de uso de websites de compra da Internet possui efeito direto e positivo sobre o nível de controle percebido pelo consumidor.

Por sua vez, a customização é a capacidade de um varejista online de adaptar produtos, serviços e o meio ambiente transacional para determinado cliente individualmente (SRINIVASAN; ANDERSON; PONNAVOLU, 2002). Os autores definem a customização sob um ponto de vista operacional, sendo a medida em que um consegue adaptar a escolha dos produtos, serviços e experiência de compras online para seus clientes. Já Rose et al. (2012) citam em sua definição de customização a possibilidade de o consumidor personalizar o website do varejista online tanto na aparência, quanto em funcionalidades. Esta permissão de customização confere aos consumidores mais controle (CHANG; YUAN; HSU, 2010; SRINIVASAN et al., 2002; DING; KEH, 2016; YOO; PARK, 2016; UMASHANKAR; BHAGWAT; KUMAR, 2017). Já segundo Kahn (1998), os consumidores são capazes de completar suas operações de forma mais eficiente quando o website é personalizado. Uma grande variedade de produtos pode irritar os consumidores e levá-los a regras de decisão simplistas para limitar as alternativas. O estudo de Wolf e Zhang (2016) também aponta para diferenças dos gêneros diante da possibilidade de customizar serviços.

Peppers e Rogers (2016) ressaltam que para poder tratar cada cliente de forma diferenciada, a organização precisa conhecê-los e diferenciá-los, reconhecendo-os em cada ponto de contato, o que reforça as vantagens da customização de websites. Já Ding e Keh (2016) afirmam que customização dos serviços traz como desvantagem maior risco percebido, e que consumidores com uma meta hedônica tendem a preferir serviços personalizados, enquanto aqueles com uma meta utilitária tendem a preferir serviços padronizados. Sendo assim, a seguinte hipótese é sugerida:

H2: Quanto maior a possibilidade de customização de websites de compras na Internet, maior será o nível de controle percebido pelos clientes.

Rose et al. (2012) definem conectividade como a habilidade de se conectar e compartilhar conhecimento e ideias com outras pessoas em uma comunidade virtual. Vale ser ressaltado que as comunidades virtuais representam um conceito muito mais amplo do que o 
boca-a-boca, sendo este geralmente definido como as comunicações dirigidas a outros consumidores sobre a posse, uso e características de produtos e serviços específicos ou seus vendedores (Bagozzi ; Dholakia, 2002; YOON; SEO; CHOI, 2017). Portanto, a crescente expansão das comunidades virtuais deriva de seu forte potencial de comunicação e marketing (YAN; WU; WANG; WU; CHEN; WEI, 2016). O ato de poder compartilhar conhecimentos com outros clientes de determinados websites de compras conferem aos consumidores um maior nível de controle da situação, pois recebem informações não apenas do vendedor, mas também de outros clientes, os quais não se beneficiam diretamente da venda de determinado produto (DUARTE; SILVA; FERREIRA, 2018), o que põe em xeque uma disputa entre websites de comércio eletrônico ou redes sociais (YAN et al., 2016).

A possibilidade de compartilhamento de experiências com outros usuários possibilita também ao consumidor, acesso a informações que sozinho o varejista não conseguiria prover, diminuindo seu nível de incerteza e, consequentemente, aumentando o seu nível de controle percebido (KIM; JIN, 2006; BAI; MARSDEN; ROSS JR; WANG, 2017), melhorando suas decisões a respeito de ofertas diárias, o que se verifica sobretudo no contexto da rede centrada em informações (information-centric), da computação em nuvem (cloud computing) e da conectividade aberta. Recentemente Hubert, Blut, Brock, Backhaus e Eberhardt (2017) atestam a relação entre a conectividade e os diferentes contextos de aplicações (apps) online. Dessa maneira, a seguinte hipótese é sugerida:

H3: Quanto maior o nível de conectividade ao utilizar websites de compra da Internet, maior o controle percebido.

Desta forma, conforme explanação anterior, segundo Rose et al. (2012), a variável controle percebido terá um efeito mediador sobre outras três variáveis: facilidade de uso, customização e conectividade. O controle percebido refere-se a uma capacidade do indivíduo perante uma ótica mais situacional, percebendo que pode alterar significantemente a situação (PACHECO; LUNARDO; SANTOS, 2013). O conceito de controle percebido surge na década de 1990, quando foi apontada sua influência positiva na satisfação e na confiança do consumidor (WATHIEU et al., 2002; PACHECO et al., 2013), o que se mostra relevante devido ao forte efeito que a satisfação e a confiança possuem nas futuras escolhas dos consumidores (WOODRUFF; CADOTTE; JENKINS, 1983; MARAKANON; PANJAKAJORNSAK, 2017; YILDIZ, 2017). Portanto, quanto maior for esse sentimento de controle, mais positiva será a 
sua experiência e consequentemente sua satisfação e confiança (GENTILE; SPILLER; NOCI, 2007; KOUFARIS; AJIT KAMBIL, 2011). Sendo assim, as seguintes hipóteses são sugeridas:

H4: Quanto maior o nível de controle percebido ao utilizar websites de compra da Internet, maior a satisfação do consumidor.

H5: Quanto maior o nível de controle percebido ao utilizar websites de compra da Internet, maior a confiança do consumidor.

O ato de comprar na Internet pode também trazer alguns benefícios para o consumidor. Ressalta-se por exemplo, a conveniência, que foi ainda mais elevada com a chegada dos aparelhos móveis - celulares e tablets (RODRÍGUEZ-TORRICO; SAN-MARTÍN; SAN JOSÉCABEZUDO, 2019). Em termos gerais, Chen e Dubinsky (2003), assim como RodríguezTorrico et. al. (2019), enumeram uma séria de benefícios obtidos ao se comprar online ligados à conveniência, dos quais são possíveis destacar, a facilidade de comparação de preços, o maior acesso a informações se comparado ao varejo físico e a não necessidade de deslocamento que, consequentemente gera uma economia de tempo e recursos à experiência do consumidor, e que, quando positivas, afetam a satisfação e a confiança dos mesmos (CHILDERS et al., 2002; GENTILE et al., 2007; ROSE et al., 2012). Dessa maneira, propõe-se as seguintes hipóteses:

H6: Quanto maior o nível de benefícios percebidos de websites de compra da Internet, maior a satisfação do consumidor.

H7: Quanto maior o nível de benefícios percebidos de websites de compra da Internet, maior a confiança do consumidor.

A satisfação do consumidor tem sido um conceito central nas pesquisas de marketing nas últimas décadas, tendo sido realizados inúmeros estudos sobre o conceito em si, analisando seus antecedentes e implicações (HEITMANN; LEHMANN; HERRMANN, 2007). De acordo com os autores, a relação positiva entre a satisfação do consumidor e a receita das organizações é um dos principais assuntos investigados, o que também é corroborado por estudos mais recentes, como o de Nisar e Prabhakar (2017).

No entanto, algumas definições de satisfação baseiam-se no paradigma seminal da desconfirmação (OLIVER, 1980), o qual refere-se à comparação entre as expectativas do 
consumidor e o desempenho percebido. Assim, no comércio eletrônico, a satisfação pode ser definida como o julgamento dos clientes frente às suas experiências com o varejista online (SZYMANSKI; HISE, 2000; NISAR; PRABHAKAR, 2017). Segundo Anderson e Srinivasan (2003) a satisfação online é "o grau de contentamento com relação à experiência de compra anterior do cliente em uma determinada empresa de comércio eletrônico". Ela depende de variáveis pessoais, como a familiaridade, a segurança percebida ao efetuar a transação, as propriedades dos websites (em relação ao valor utilitário percebido pelos clientes), e as funcionalidades de navegação que o mesmo oferece (YOON, 2002).

Visando a alavancagem de vantagem competitiva (MITTAL; KAMAKURA, 2001), o aumento da satisfação dos clientes é um objetivo estratégico de muitas empresas, porém, o aumento do nível de satisfação dos clientes deve compensar o investimento realizado. No entanto, satisfação é um conceito multidimensional, podendo ser percebido em diferentes níveis: satisfação com o produto em si, incluindo a avaliação dos consumidores do seu desempenho; satisfação com o processo de vendas, incluindo interações com a equipe de venda (varejo físico) e com o website de compras da Internet (varejo online); e satisfação com o serviço pós-venda, incluindo a qualidade do serviço, gestão de trocas, devoluções e reclamações (HOMBURG; GIERING, 2001). Ainda, dois tipos de componentes da satisfação são apresentados por Yu e Dean (2001), os cognitivos e os afetivos. O primeiro ocorre quando os clientes criam expectativas anteriores ao consumo, observam o produto e seus atributos, formam percepções e as comparam com suas expectativas, realizando o julgamento da satisfação. Já o segundo refere-se aos atributos pós-compra, incluindo dois estados: (i) sucesso (quando o consumidor obteve um afeto positivo em relação a compra o que gera componentes emocionais como felicidade e surpresa), e (ii) fracasso (quando o consumidor obteve um afeto negativo em relação a sua compra, podendo gerar sentimento de tristeza e decepção). $\mathrm{Na}$ literatura nacional, a experiência de compra e satisfação de clientes ligados à intenção de recompra pode ser evidenciada em alguns trabalhos recentes (ALVES, 2018; LIMA; MILAN; GRACIOLA; DE TONI, 2018).

Dada a ocorrência de satisfação online geral frente a experiências anteriores cria-se atitude positiva com relação a um determinado website e lealdade ao mesmo (ANDERSON; SRINIVASAN, 2003; HA et al., 2010; LIANG; CHOI; JOPPE, 2018). Sendo assim, a satisfação do consumidor é considerada um conceito chave da lealdade no contexto do varejo (ROSE et al., 2012; VALVI; FRAGKOS, 2012; LIANG; CHOI; JOPPE, 2018). Segundo Rose et al. (2012), existem evidências que tanto a satisfação quanto a confiança influenciam a lealdade do consumidor, e consequentemente sua intenção de recompra online. Porém alguns 
autores consideram que a satisfação nem sempre têm efeito direto na intenção de recompra. No presente estudo será utilizada a visão de Ha, Janda e Muthaly (2010) e de Liang, Choi e Joppe (2018), que afirmam que a satisfação possui efeito indireto na intenção de recompra via confiança. Dessa maneira, propõe-se a seguinte hipótese:

H8: Quanto maior o nível de satisfação do consumidor ao comprar online, maior o nível de confiança do cliente ao comprar online.

A confiança e suas relações no mundo off-line tem sido um tema de pesquisa de várias disciplinas como filosofia, sociologia, fisiologia, gestão, marketing e comércio eletrônico desde os anos 1950 (SINGH; SIRDESHMUKH, 2000; URBAN; AMYX; LORENZON, 2009; RAZAK; MARIMUTHU; OMAR; MAMAT, 2014). Portanto, a literatura sobre confiança é bastante extensa, tendo sido produzidos diferentes conceitos, definições e conclusões, a depender da disciplina.

A segurança e a privacidade das transações online trazem à tona a necessidade de confiança (Urban et al., 2009). Mais especificamente, para ambientes de compras online, a confiança do consumidor relaciona-se a sentimentos de vulnerabilidade, que são exacerbados devido à natureza remota do relacionamento com o varejista (ROSE et al., 2012). Segundo Chen e Dibb (2010), estes sentimentos podem ser experimentados pelos internautas devido a não terem controle sobre o acesso de outros às suas informações pessoais, assim como não terem a possibilidade de tocar, sentir ou experimentar os produtos ao realizar a compra. Ndubisi, Lee e Eze (2011) apontam para o papel exercido pela confiança do cliente na manutenção de relacionamentos de longo prazo com o varejista, sendo que a falta de confiança é considerada como a maior barreira à realização de transações online (URBAN et al., 2009). Ainda segundo os autores, para adquirir e reter consumidores online e construir uma vantagem competitiva, os varejistas são desafiados a criarem e manterem um clima de confiança. Portanto, existe confiança quando uma das partes tem uma forte convicção de que a outra parte é íntegra e irá cumprir os compromissos prometidos (MORGAN; HUNT, 1994). Já a falta de confiança reduz a chance de compradores se envolverem em transações online ou no ato de recompra (CHIU et al., 2009, 2012). Recentemente, os estudos de Vallejo, Redondo e Acerete (2016) e de Liang, Choi e Joppe (2018) colocam a confiança como aspecto central da relação entre consumidores e recompra online. Dessa maneira, propõe-se a seguinte hipótese: 
H9: Quanto maior o nível de confiança do consumidor ao comprar online, maior a intenção de recompra.

Para verificar as hipóteses indicadas anteriormente, foi empregado o modelo proposto abaixo (figura 1).

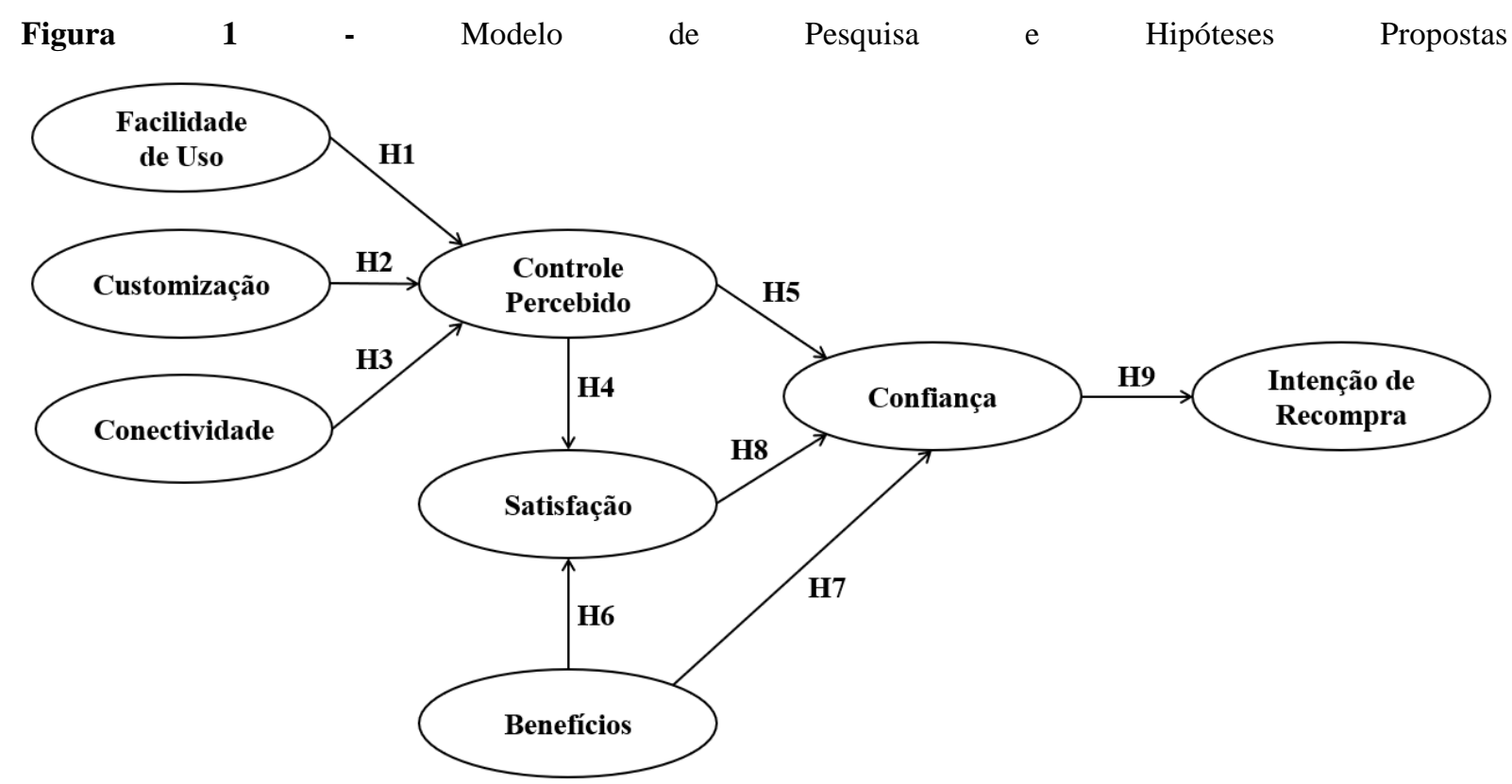

\section{MÉTODO}

\subsection{OPERACIONALIZAÇÃO DAS VARIÁVEIS}

Para o teste das hipóteses foi realizada uma cross-sectional survey com a população de interesse (HAIR; ROSE; CLARK, 2009), composta por consumidores brasileiros, com acesso à Internet e que já tivessem realizado compras online. A operacionalização das variáveis foi feita por meio do uso de escalas já elaboradas e testadas na literatura, para a medição de todos os construtos envolvidos no modelo proposto. O instrumento de pesquisa foi composto por 33 itens, sendo medidos via escalas do tipo Likert de 5 pontos, variando de "discordo totalmente" a "concordo totalmente", sendo os itens de escala traduzidos para o português por dois profissionais, seguindo-se a checagem por tradução reversa (BRISLIN, 1970). Posteriormente, foram realizados dois pré-testes com 10 e 20 pessoas da população de interesse, para ajuste de perguntas e layout do questionário. 
As escalas utilizadas foram baseadas na literatura e composta pelos seguintes construtos: conectividade, customização e controle percebido (ROSE et al., 2012, quatro itens em cada escala), facilidade de uso (ROSE et al., 2012, com cinco itens), benefícios percebidos (TEO, 2002, com quatro itens), confiança online (LEE; TURBAN, 2001, com quatro itens), satisfação online e intenção de recompra online (KHALIFA; LIU, 2007, também com quatro itens cada). O instrumento de pesquisa foi dividido em três partes: (i) seis itens para medir as variáveis demográficas dos respondentes, (ii) 10 perguntas para se levantar os hábitos de uso da Internet e (iii) 33 itens utilizados para medir os construtos. A Tabela 1 apresenta os itens utilizados para a mensuração de cada construto, oriundos de escalas previamente testadas da literatura (ROSE et al., 2012; TEO, 2002; LEE; TURBAN, 2001; KHALIFA; LIU, 2007).

Tabela 1: Itens utilizados para mensuração das escalas

\begin{tabular}{|c|c|}
\hline Sigla & Itens por construto \\
\hline \multicolumn{2}{|r|}{ Conectividade (CONE) - Rose et al., 2012} \\
\hline CONE1 & $\begin{array}{l}\text { É uma vantagem quando o conteúdo de sites de compras da Internet é parcialmente } \\
\text { influenciado pela comunidade que o utiliza. }\end{array}$ \\
\hline CONE2 & $\begin{array}{l}\text { Ser capaz de conectar com outros consumidores que compartilham interesses semelhantes } \\
\text { nos mesmos produtos é uma característica positiva de compras pela Internet. }\end{array}$ \\
\hline CONE3 & $\begin{array}{l}\text { Ser capaz de compartilhar comentários sobre minhas experiências sobre os produtos com } \\
\text { outros consumidores em sites de compras pela Internet é uma característica importante para } \\
\text { mim. }\end{array}$ \\
\hline CONE4 & $\begin{array}{l}\text { Visualizar as recomendações de produtos de outros consumidores que usam sites de compra } \\
\text { pela Internet é útil. }\end{array}$ \\
\hline \multicolumn{2}{|r|}{ Customização (CUST) - Rose et al., 2012} \\
\hline CUST1 & $\begin{array}{l}\text { Sites de compras da Internet deveriam dar a impressão que estão falando comigo } \\
\text { pessoalmente como um cliente. }\end{array}$ \\
\hline CUST2 & $\begin{array}{l}\text { O requisito de efetuar login em um site de compras pela Internet faz-me sentir reconhecido } \\
\text { como um cliente. }\end{array}$ \\
\hline CUST3 & $\begin{array}{l}\text { É importante que ao utilizar um site de compras pela Internet eu sinta ele como uma área } \\
\text { customizada para mim. }\end{array}$ \\
\hline CUST4 & $\begin{array}{l}\text { Eu gosto quando é possível personalizar sites de compras pela Internet segundo o meu } \\
\text { próprio gosto. }\end{array}$ \\
\hline \multicolumn{2}{|r|}{ Controle Percebido (CONT) - Rose et al., 2012} \\
\hline CONT1 & Eu me sinto no controle do que estou fazendo quando realizo compras em sites da Internet. \\
\hline CONT2 & $\begin{array}{l}\text { Eu posso facilmente controlar as informações que são fornecidos em sites de compras pela } \\
\text { Internet. }\end{array}$ \\
\hline CONT3 & $\begin{array}{l}\text { Eu sinto que posso controlar as informações fornecidas a mim em sites de compras da } \\
\text { Internet. }\end{array}$ \\
\hline CONT4 & $\begin{array}{l}\text { O nível de informações fornecidas por sites de compras na Internet me ajuda a sentir no } \\
\text { controle da decisão de compra. }\end{array}$ \\
\hline \multicolumn{2}{|r|}{ Facilidade de Uso (PEOU) - Rose et al., 2012} \\
\hline PEOU1 & A navegação é rápida e fácil quando eu compro na Internet. \\
\hline PEOU2 & Comprar pela Internet permite-me facilmente adquirir o que eu quero. \\
\hline PEOU3 & É fácil torna-se confiante em comprar pela Internet. \\
\hline PEOU4 & Sites de compras na Internet são fáceis de usar. \\
\hline PEOU5 & Aprender a navegar em sites de compras na Internet não demora muito para mim. \\
\hline \multicolumn{2}{|r|}{ Benefícios Percebidos (BENE) - Teo, 2002} \\
\hline BENE1 & $\begin{array}{l}\text { Eu posso saber quais são os produtos adequados para as minhas necessidades em comparação } \\
\text { com os outros produtos concorrentes utilizando sites de compras pela Internet. }\end{array}$ \\
\hline
\end{tabular}




\begin{tabular}{|c|c|}
\hline BENE2 & $\begin{array}{l}\text { Com sites de compras pela Internet posso descobrir o que eu quero saber antes de comprar } \\
\text { online. }\end{array}$ \\
\hline BENE3 & $\begin{array}{l}\text { Revisando as informações recebidas por sites de compras pela Internet eu consigo ter certeza } \\
\text { de que fiz a melhor decisão de compra. }\end{array}$ \\
\hline BENE4 & Um dos principais benefícios de comprar na Internet é a conveniência. \\
\hline \multicolumn{2}{|r|}{ Confiança Online (CONF) - Lee \& Turban, 2001} \\
\hline CONF1 & Comprar pela Internet é confiável. \\
\hline CONF2 & $\begin{array}{l}\text { Em geral, acredito que sites de compras na Internet irão cumprir as promessas que eles } \\
\text { fazem. }\end{array}$ \\
\hline CONF3 & Posso confiar em compras pela Internet, não existem incertezas. \\
\hline CONF4 & Comprar pela Internet é uma experiência confiável. \\
\hline \multicolumn{2}{|r|}{ Satisfação Online (SATS) - Khalifa \& Liu, 2007} \\
\hline SATS1 & De maneira geral estou satisfeito com as minhas experiências de compras pela Internet. \\
\hline SATS2 & $\begin{array}{l}\text { Estou satisfeito com a experiência pré-compra em sites de compras da Internet. (Por exemplo: } \\
\text { pesquisa de produtos, qualidade de informação dos produtos, comparação de produtos etc.). }\end{array}$ \\
\hline SATS3 & $\begin{array}{l}\text { Estou satisfeito com a experiência de compra em sites de compras da Internet. (Por exemplo: } \\
\text { pedidos, processamento de pagamento etc.). }\end{array}$ \\
\hline SATS4 & $\begin{array}{l}\text { Estou satisfeito com a experiência pós-compra em sites de compras pela Internet. (Por } \\
\text { exemplo: suporte ao cliente, suporte pós-vendas, políticas de retorno/reembolsos, entregas } \\
\text { etc.). }\end{array}$ \\
\hline
\end{tabular}

Intenção de Recompra Online (INT) - Khalifa \& Liu, 2007

\begin{tabular}{l|l}
\hline INT1 & É provável que eu compre nos mesmos sites de compras pela Internet num futuro próximo. \\
\hline INT2 & Prevejo que eu compre nos mesmos sites de compras pela Internet num futuro próximo. \\
\hline INT3 & Eu regularmente compro os mesmos sites de compras na Internet. \\
\hline INT4 & Espero comprar novamente dos mesmos sites de compras pela Internet num futuro próximo. \\
\hline
\end{tabular}

Com relação aos procedimentos de análise dos dados, todos os resultados obtidos com a aplicação do instrumento de pesquisa foram consolidados em uma base de dados e analisados via os softwares SPSS (cálculo de estatísticas descritivas e do alfa de Cronbach, organização e limpeza dos dados) e AMOS (realização da análise fatorial confirmatória e da modelagem de equações estruturais). Com o intuito de avaliar as propriedades dos construtos presentes no instrumento de pesquisa, particularmente no que diz respeito à unidimensionalidade, confiabilidade e validade, foi estimado, em um primeiro passo, o modelo de mensuração com os construtos utilizados por meio de uma análise fatorial confirmatória (CFA) com os dados obtidos (Hair et al., 2009). Garantidas as validades de face, nomológica, convergente e discriminante dos construtos, foi realizado o teste das hipóteses do modelo proposto via modelagem de equações estruturais com o software AMOS.

\subsection{AMOSTRA E PROCEDIMENTOS DE COLETA DE DADOS}

A amostragem empregada foi não probabilística de conveniência (HAIR; ROSE; CLARK, 2009) a fim de realizar o teste das hipóteses formuladas para o estudo. A coleta de dados ocorreu por meio de questionários auto-administrados, disponibilizados e respondidos em um website de pesquisas (Qualtrics). Todos os respondentes foram convidados a participar 
da pesquisa via postagens em redes sociais ou e-mails contendo o link da pesquisa. Obteve-se 395 respostas, sendo eliminados 97 questionários por apresentarem dados ausentes, 25 por conta de os respondentes não terem realizados compras na Internet nos últimos 12 meses, e 23 respondentes que apresentavam idade acima de 60 anos. A amostra final foi composta por 250 questionários válidos preenchidos por pessoas entre 18 e 60 anos, com compras online realizadas nos últimos 12 meses.

Dos 250 questionários válidos, 142 foram do sexo feminino (56,8\%) e 108 do sexo masculino (43,2\%). Em relação ao estado civil, 136 respondentes $(54,4 \%)$ eram solteiros, 92 casados $(36,8 \%)$ e os demais $22(8,8 \%)$ pertencentes a outros estados civis. Já em relação à renda, 131 indicaram renda familiar mensal superior a dez mil reais $(52,4 \%)$, enquanto outros 66 respondentes (ou 24,6\%) afirmaram ter renda familiar entre seis e dez mil reais. Quanto a seu perfil etário, a maioria dos respondentes $(n=139$, ou 55,6\%) possuía entre 18 e 34 anos, enquanto os demais $(44,4 \%)$ tinham idade entre 35 e 60 anos. A média de idade observada foi de 36,1 anos.

Além do dado sócio- demográficos, foram levantadas também algumas informações sobre os hábitos de uso da Internet dos respondentes. Quando perguntados se preferiam comprar sempre dos mesmos websites ou experimentar websites novos, $85 \%$ dos respondentes afirmaram preferir comprar sempre dos mesmos. Na média, os entrevistados fizeram uma compra pela Internet a cada 2 meses e cerca de $16 \%$ dos respondentes disseram haver realizado alguma compra nas últimas 24 horas (80\% nos últimos 30 dias).

\section{ANÁLISE E RESULTADOS}

\subsection{TESTE DE VARIÂNCIA COMUM DO MÉTODO}

A variância comum do método (CMV) pode gerar problemas ao se considerar que todos itens, variáveis dependentes e independentes, foram oriundas de opiniões coletadas dos mesmos respondentes. Dessa forma, o teste de um fator de Harman foi empregado, seguindo as sugestões de Podsakoff e Organ (1986), a fim de identificar se haveria esse viés nos dados da pesquisa. Portanto, os resultados da análise de componentes principais indicaram a presença de oito fatores com valor próprio superior a 1 . Ao mesmo tempo, nenhum dos fatores representava quase toda a variação (o fator que explicava mais capturava apenas $21 \%$ da variação total). Dados esses resultados, conforme descrito por Podsakoff e Organ (1986), a variância do método comum parece não ter apresentado problemas neste estudo. 


\subsection{AVALIAÇÃO DO MODELO DE MENSURAÇÃO}

Foi realizada uma análise fatorial confirmatória (CFA) visando testar a validade, unidimensionalidade e confiabilidade das escalas usadas no presente modelo de mensuração. Para avaliar o fit do modelo de mensuração proposto, alguns índices de ajuste foram utilizados (tanto incrementais quanto absolutos). O modelo inicial completo (com todos 33 itens) não apresentou bons índices de ajuste, com um RMSEA (mean-squared error of approximation) de 0,064 (com C.I de 0,059 até 0,07), um CFI (comparative fit index) de 0,844, um IFI (incremental fit index) de 0,847, um TLI (Tucker-Lewis index) de 0,824 e um valor significativo para índice quiquadrado $(\chi 2=993,14$, d.f. $=467, \mathrm{p}<0,001, \chi 2 / \mathrm{d} \mathrm{f}$. = 2,12). Portanto, após diversas iterações de refino do modelo, chegou-se ao modelo de mensuração final, com 24 indicadores, mantendo-se cada uma das oito escalas com pelo menos três itens. Este modelo de mensuração final (com 24 itens) apresentou índices melhores de ajuste com um RMSEA de 0,057 (C.I de 0,048 até 0,065), um CFI de 0,92, um IFI de 0,92, um TLI de 0,90 e um valor significativo para o índice quiquadrado $(\chi 2=420,46$, d.f. $=224, p<0,001, \chi 2 /$ d.f. $=1,87$. Os índices finais apresentados sugerem um ajuste satisfatório do modelo quando avaliados em conjunto (Hu; Bentler, 1999).

A validade de face para todas as escalas utilizadas foi garantida durante $o$ desenvolvimento do instrumento de pesquisa (escolha de escalas já utilizadas na literatura, tradução cuidadosa e pré-testes). Para verificar a validade nomológica foi analisada a matriz de correlação entre construtos, com todas as correlações sendo significativas e estando na direção esperada. No que diz respeito à validade convergente, foi calculada a variância extraída média para cada construto (AVE). Todos os valores de AVE calculados estavam entre 0,50 e 0,71, evidenciando a validade convergente das escalas utilizadas. Já no que diz respeito à consistência interna e confiabilidade das escalas utilizadas, todas elas atenderam aos níveis mínimos de confiabilidade considerados adequados pela literatura (FORNELL; LARCKER, 1981), apresentando valores entre 0,70 e 0,87 para o coeficiente alfa e entre 0,70 e 0,88 para a confiabilidade composta. Por fim, todas as variâncias compartilhadas foram inferiores à variância extraída pelos itens que medem os construtos, indicando validade discriminante adequada. Os valores dos alfas de Cronbach, confiabilidades compostas e AVEs, juntamente com as médias e desvios padrões de cada construto são apresentados na Tabela 2. 
Tabela 2: Média, Desvio Padrão, Alfa de Cronbach (Alfa), Confiabilidade Composta (CR) e Variância Extraída Média (AVE) para cada construto

\begin{tabular}{l|c|c|c|c|c}
\hline Construto & Média & Desvio & Alfa & CR & AVE \\
\hline Customização & 3,52 & 0,72 & 0,72 & 0,75 & 0,51 \\
\hline Conectividade & 3,95 & 0,87 & 0,70 & 0,70 & 0,50 \\
\hline Facilidade de Uso & 3,83 & 0,78 & 0,80 & 0,77 & 0,52 \\
\hline Controle Percebido & 3,17 & 0,87 & 0,73 & 0,76 & 0,53 \\
\hline Satisfação & 3,94 & 0,68 & 0,71 & 0,71 & 0,50 \\
\hline Intenção de Recompra Online & 4,39 & 0,69 & 0,87 & 0,88 & 0,71 \\
\hline Confiança Online & 3,18 & 0,88 & 0,80 & 0,82 & 0,60 \\
\hline Benefícios Percebidos & 4,19 & 0,68 & 0,76 & 0,77 & 0,53 \\
\hline
\end{tabular}

\subsection{ANÁLISE DO MODELO ESTRUTURAL}

A técnica de modelagem de equações estruturais (SEM) foi utilizada, por meio do software AMOS, para testar o modelo proposto e as hipóteses da pesquisa. Todos os índices indicaram um bom ajuste do modelo aos dados. A razão $\chi 2 /$ d.f. foi de 2,808 (682,23, d.f. $=243$, $\mathrm{p}<0,001$ ), inferior ao valor de 3,0 sugerido por Byrne (2016). Além disso, os índices de ajuste incrementais foram maiores do que 0,90, com um CFI (comparative fit index) de 0,91, um TLI (Tucker-Lewis index) de 0,90 e um IFI (incremental fit index) de 0,91. Por sua vez, os índices de ajuste absoluto apresentaram valores abaixo do limite de 0,08 estabelecido pela literatura (Hair et al., 2009), indicando também um bom ajuste do modelo. O RMSEA (root mean-square error of approximation) foi de 0,065 (C.I. de 0,059 a 0,071) e o SRMR (standardized root mean-square residual) foi de 0,078. Dados esses índices, conclui-se que o ajuste do modelo proposto é satisfatório. Após a verificação do ajuste dos modelos de mensuração e estrutural propostos, foram avaliados os coeficientes estimados para as relações entre os construtos (ver Tabela 3). A verificação de cada uma das hipóteses da pesquisa foi realizada com a análise da magnitude, direção e significância dos coeficientes padronizados estimados por meio do modelo estrutural.

\subsection{TESTE DAS HIPÓTESES DE PESQUISA}


A análise da magnitude, direção e significância dos coeficientes padronizados estimados por meio do modelo estrutural foi realizada para cada uma das hipóteses da pesquisa realizada. As relações cujo p-valor para o teste testava menor que um nível de significância de 0,05 , apresentaram relação significativa entre os construtos (BYRNE, 2016). Portanto, conforme a Tabela 3, das 10 hipóteses formuladas, 5 obtiveram suporte empírico, ou seja, apresentaram relações significativas entre os construtos relacionados, enquanto a outra metade das hipóteses não foi verificada.

Tabela 3: Coeficientes Padronizados Estimados, Hipóteses e Significâncias para o Modelo Proposto

\begin{tabular}{l|c|c|c}
\hline Relação Proposta & $\begin{array}{c}\text { Coeficiente } \\
\text { Padronizado }\end{array}$ & p-valor & $\begin{array}{c}\text { Hipótese } \\
\text { Verificada }\end{array}$ \\
\hline H1: Facilidade de Uso > Controle Percebido & 0,542 & $<0,001$ & Sim \\
\hline H2: Customização > Controle Percebido & 0,165 & 0,08 & Não \\
\hline H3: Conectividade > Controle Percebido & $-0,053$ & 0,77 & Não \\
\hline H4: Controle Percebido > Satisfação & 0,066 & 0,11 & Não \\
\hline H5: Controle Percebido > Confiança & 0,233 & $<0,001$ & Sim \\
\hline H6: Benefícios Percebidos > Satisfação & 0,746 & $<0,001$ & Sim \\
\hline H7: Benefícios Percebidos > Confiança & 0,066 & 0,69 & Não \\
\hline H8: Satisfação > Confiança & 0,574 & 0,001 & Sim \\
\hline H9: Confiança > Intenção de Recompra Online & 0,244 & 0,001 & Sim \\
\hline
\end{tabular}

\section{DISCUSSÃO}

O resultado da modelagem realizada estabelece que, dos três construtos propostos como antecedentes do controle percebido, apenas a facilidade de uso obteve efeitos significativos sobre esta variável mediadora. Sendo assim, a hipótese 1 foi confirmada e tal achado vai de acordo com o estudo de Cheung et al. (2005) e Chiu et al. (2009) e fortalece a noção de que a facilidade de uso afeta direta e positivamente o controle percebido.

Por sua vez, a customização não apresentou efeitos significativos ( $\mathrm{p}$-valor $=0,77)$ sobre o controle percebido, não confirmando a hipótese 2 e sendo um resultado inesperado e inconsistente com os achados de Rose et al. (2012) e Chang et al. (2010). Uma possível razão é que o consumidor enxergue a grande possibilidade de customização como um fator que diminui o controle percebido, talvez pelo fato de que, ao serem apresentadas tantas opções de customização, o consumidor termine por se sentir "perdido" no meio de tantas escolhas. 
Reduzir as opções de customização nesse caso, passaria uma sensação maior de controle percebido para o consumidor, pois ele terá certeza de que estará vendo todo o conteúdo a ser exposto da maneira correta. Um exemplo ocorre com os softwares operacionais mobile iOS da Apple e Android do Google. O primeiro possui muito menos opções de customização do que o segundo, e não necessariamente o consumidor do Android sente um maior controle percebido, pode ocorrer até o contrário no caso de ele se deparar com muitas opções de customização quem não domina e se sentir menos no controle do que um usuário de um software mais simples em relação a possibilidade de customização, o como o iOS da Apple. Ainda, segundo Ding e Keh (2016), consumidores com metas utilitárias podem tender a preferir serviços padronizados, e não customizados.

A hipótese 3 também não foi confirmada, tendo a conectividade não apresentado efeitos significativos ( $\mathrm{p}$-valor $=0,77)$ no nível de controle percebido do consumidor, contrariando os resultados encontrados por Rose et al. (2012), Kim e Jin (2006) e Pentina et al. (2008). Uma possível razão para esse achado seria uma percepção, por parte dos consumidores, de que os comentários realizados em websites de compra da Internet não são imparciais, ou seja, pessoas podem fornecer informações com outros interesses que não sejam puramente compartilhar experiências e conhecimento. Outro ponto é a realização do estudo no Brasil, onde a conectividade é mais limitada, dadas as velocidades de conexão e infraestrutura de internet no país.

A hipótese 4, que buscava medir a relação entre controle percebido e satisfação também não apresentou efeitos significativos $(\mathrm{p}$-valor $=0,72)$ indo em desencontro com o que foi observado por Gentile et al. (2007), Koufaris et al. (2011) e Guo, Lotz, Tang e Gruen (2016). A razão disto pode ser o fato de não ter sido solicitado ao participante que pensasse em um website específico ao responder o questionário. Sendo assim, um problema pontual que um respondente tenha tido com determinado website e que o tenha levado a ficar insatisfeito apesar de ter se sentido no controle da situação durante a compra, pode afetar o resultado. Ademais, Liang, Choi e Joppe (2018) distinguem a satisfação baseada em transações da satisfação baseada em experiências.

O controle percebido apresentou efeito significativo e positivo em relação à confiança, o que vai de acordo com os resultados observados por de Gentile et al. (2007), Koufaris et al. (2011) e Pacheco (2013), confirmando a hipótese 5 e fortalecendo a noção de que quanto maior o controle percebido pelo consumidor, maior será o nível de confiança do mesmo. Tal resultado também corrobora com estudos mais recentes (por exemplo, ASHRAF; THONGPAPANL; 
SPYROPOULOU, 2016; OZTURK; BILGIHAN; NUSAIR; OKUMUS, 2016; ELKASEH; WONG; FUNG, 2016).

A hipótese 6 também foi confirmada, indicando que os benefícios percebidos possuem efeitos significativos e positivos em relação à satisfação do consumidor, indo de acordo com os estudos de Childers et al. (2002), Gentile et al. (2007) e Rose et al. (2012). Quanto maior os benefícios percebidos pelo consumidor, maior será a satisfação dele. A magnitude deste efeito foi a maior entre todos os construtos $(0,738)$.

Benefícios percebidos não apresentaram efeitos significativos na confiança do consumidor, indo em desencontro aos resultados achados por Childers et al. (2002), Gentile et al. (2007) e Rose et al. (2012). Sendo assim a hipótese 7 não foi confirmada. O fato de não ter sido solicitado ao respondente que pensasse em um website específico ao responder pode também ter afetado este resultado, uma vez que alguma experiência negativa singular em relação à confiança que o participante possa ter tido, mesmo tendo observado diversos benefícios na transação, pode ter afetado o resultado em geral. Liang, Choi e Joppe (2018), por sua vez, distinguem a confiança baseada na instituição (no caso no Airbnb) da disposição para confiar (nos hóspedes). Portanto, essa nuance pode não ter sido captada no modelo.

De acordo com os resultados apresentados por Rose et al. (2012) e Valvi e Fragkos (2012) e de Liang, Choi e Joppe (2018), o nível de satisfação do consumidor apresentou efeitos significativos sobre a confiança do consumidor, corroborando com os resultados apresentados no trabalho de Ha et al. (2010) e dos demais autores citados. Pode-se afirmar então que, quanto maior o nível de satisfação do consumidor ao comprar online, maior o nível de confiança do mesmo. Sendo assim, a hipótese 8 foi confirmada.

Por fim, a hipótese 9, que mede a relação entre a confiança e a intenção de recompra online apresentou efeitos significativos $(\mathrm{p}$-valor $=0,001$ ), resultado de acordo com os achados obtidos por Chiu et al. (2009) e de Liang, Choi e Joppe (2018), para quem a confiança, assim como verificado aqui, atua como o mediadora entre a satisfação baseada nas transações online e a intenção de recompra. Sendo assim, quanto maior a confiança do consumidor na empresa e em sua plataforma de comércio eletrônico, maior será sua intenção de recompra. De acordo com Vallejo, Redondo e Acerete (2016), em pesquisas de marketing anteriores, a confiança é composta por três dimensões importantes (honestidade, benevolência e competência), sendo primordial para a formação de relacionamentos de longo prazo com clientes, manifestos no varejo online via o ato de recompra.

De acordo com os resultados obtidos e hipóteses verificadas (H1, H5, H6, H8 e H9), é possível propor um modelo alternativo para o problema de pesquisa, incorporando somente os 
construtos cujas hipóteses foram significativas. Tal modelo, mais parcimonioso com a exclusão dos construtos Conectividade e Customização), é representado pelo diagrama da Figura 2.

Figura 2 - Modelo alternativo contendo somente as relações verificadas e construtos envolvidos

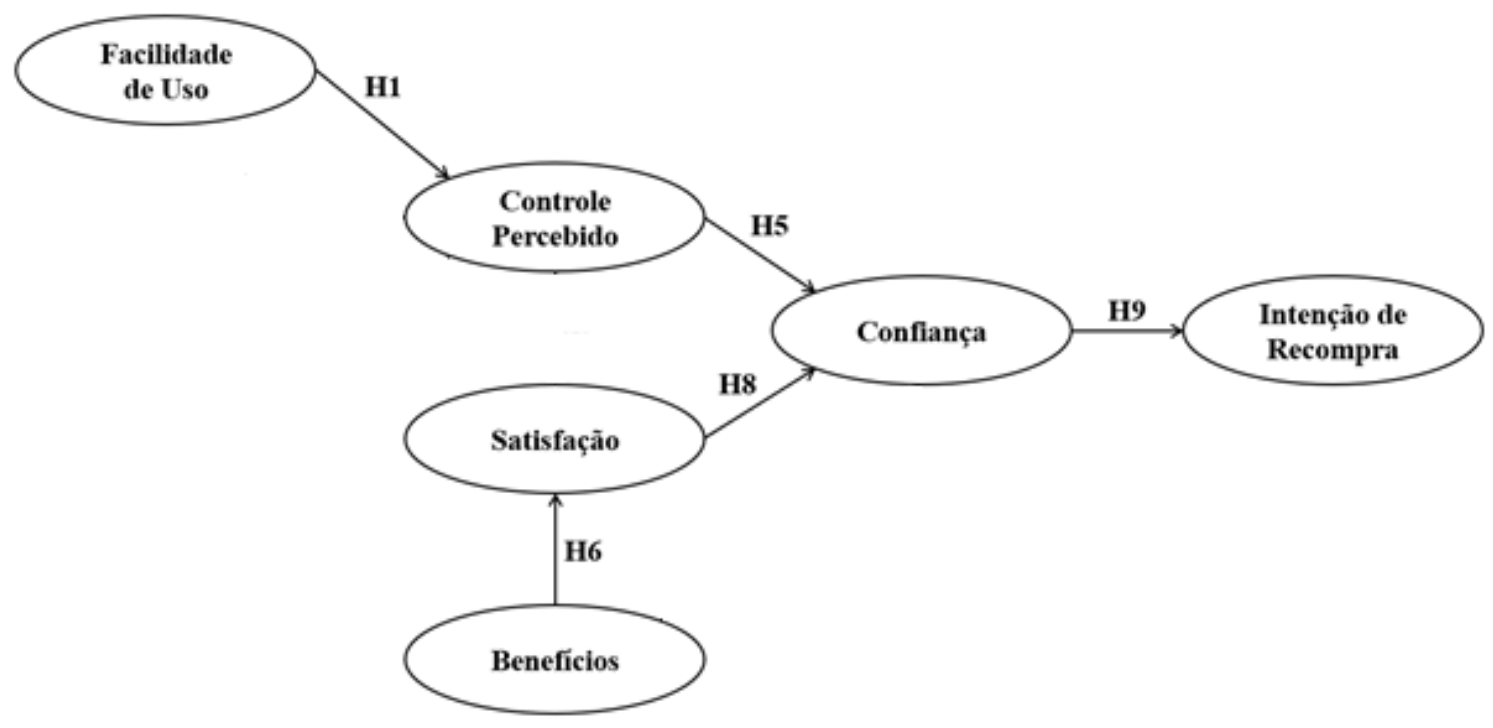

\section{CONSIDERAÇÕES FINAIS}

A intenção de recompra online é um fator chave de sucesso para o varejista online (CHOU; HSU, 2016; FANG et al., 2014). Os resultados e relações verificados na pesquisa representam contribuições relevantes para o campo do comportamento do consumidor, mais especificamente da intenção de recompra online e os fatores que a afetam. Essa questão permanece relevante na atualidade, dadas as constantes mudanças no comportamento de compra de consumidores online e as novas tecnologias de compra online que surgem a todo momento, como visto em diversos trabalhos (a exemplo de VALLEJO; REDONDO; ACERETE, 2016; CHINOMONA; MAZIRIRI, 2017; PEE; JIANG; KLEIN, 2018; LIANG; CHOI; JOPPE, 2018)

A pesquisa investigou o impacto da satisfação, confiança e seus antecedentes na intenção de recompra online, buscando melhor compreensão dos fatores determinantes que levam o consumidor a recomprar de determinado fornecedor online. Das nove hipóteses de pesquisa sugeridas, cinco foram confirmadas e quatro não apresentaram relações significativas, o que denota a complexidade e a relevância de se testar os diversos construtos em contextos distintos. 
Primeiramente, o estudo corrobora não só com os achados de Rose et al. (2012), mas também parcialmente com outros estudos mais recentes (VALVI; FRAGKOS, 2012; LIANG; CHOI; JOPPE, 2018), confirmando a relação significativa direta e positiva entre a satisfação do consumidor e confiança e da confiança com a intenção de recomprar online, indo de encontro com o que afirma Ha et al. (2010).

Em segundo lugar, o estudo também verifica a relação significativa direta e positiva entre o controle percebido do consumidor e a confiança, ou seja, reforçando os resultados dos trabalhos de Gentile et al. (2007) e Koufaris et al. (2011), indicando que quanto mais o consumidor se sentir à vontade com a experiência de compra online, navegando e controlando sem problemas a interface que o vendedor disponibilizou para a loja, maior será sua certeza de que pode confiar na empresa e terminar sua compra, com segurança e facilidade.

Por fim, os benefícios percebidos apresentaram relação significativa com satisfação do consumidor, assim como ocorreu nos trabalhos de Childers et al. (2002), Gentile et al. (2007) e Rose et al. (2012). Sendo assim, pode-se afirmar que quanto maiores os benefícios percebidos pelo consumidor, maior será a sua satisfação, indicando que empresas que vendem online devem ficar atentas com os benefícios que oferecem (em termos de comodidade, conveniência, comparação de preços e informações de produtos) para estimular o consumidor a se sentir satisfeito, atendendo suas expectativas com relação à experiência de compra online.

Quanto às suas implicações gerenciais, o estudo apresenta diversos achados que podem ser úteis para varejistas online, tais como a importância que deve ser dispensada à clareza das informações, atenção nos detalhes e navegação em websites de e-commerce. Se faz crucial o monitoramento da percepção do consumidor em relação à facilidade de uso do website. Das evidências deste estudo, a satisfação do consumidor deve ser priorizada pelas organizações dado que afeta tanto a confiança do consumidor, quanto indiretamente a intenção de recompra online. Fica claro também que a confiança é a peça central para o relacionamento de longo prazo com clientes e sua intenção de recompra, sendo crucial, portanto, que ela seja nutrida por meio de melhores interações, maior segurança e transparência da empresa. Por fim, dada a relação significativa direta e positiva do nível de benefícios percebidos com a satisfação do consumidor, as organizações devem se ater aos fatores considerados como benefícios relevantes para seus clientes.

Possíveis limitações metodológicas desta pesquisa referem-se aos critérios de amostragem, dado que a amostra por conveniência resultou em praticamente $90 \%$ dos respondentes residentes na região Sudeste do Brasil, mais de $90 \%$ com nível de escolaridade de graduação ou superior, e $80 \%$ com renda familiar média acima de $\mathrm{R} \$ 6.000,00$, o que pode 
representar vieses peculiares a estes fatores. Ainda no tocante ao procedimento de coleta de dados, o fato de não ter sido solicitado ao respondente que pensasse em um website específico ao responder o questionário, pode acarretar uma "visão geral" do respondente sobre as questões propostas, e não relativa a especificidades de determinados websites de compras.

Já quanto às pesquisas futuras, sugere-se a inclusão de novos construtos, como, por exemplo, a experiência do consumidor e o hábito do consumidor, buscando-se o enriquecimento do modelo. Por fim, seria interessante repetir o modelo em questão com uma nova amostra, maior e mais heterogênea, focando em um site de compras específico, a fim de se comparar os resultados e buscar-se a minimização de vieses decorrentes de determinadas características do universo amostral deste estudo. Outra possibilidade seria a de re-especificar o modelo para hipóteses não confirmadas, testando novas relações entre construtos, baseadas em literatura mais recente.

\section{REFERÊNCIAS}

AGARWAL, R.; KARAHANNA, E. Time flies when you're having fun: Cognitive absorption and beliefs about information technology usage. MIS quarterly, p. 665-694, 2000.

ALVES, C. A.; STEFANINI, C. J.; SILVA, L. A., \& AMARAL MORETTI S. L. O papel da experiência de compra na intenção de recompra. Revista Ciências Administrativas, v. 24, n. $2,2018$.

ANDERSON, R. E.; SRINIVASAN, S. S. E-satisfaction and e-loyalty: A contingency framework. Psychology; marketing, v. 20, n. 2, p. 123-138, 2003.

ASHRAF, A. R.; THONGPAPANL, N. T.; SPYROPOULOU, S. The connection and disconnection between e-commerce businesses and their customers: Exploring the role of engagement, perceived usefulness, and perceived ease-of-use. Electronic Commerce Research and Applications, v. 20, p. 69-86, 2016.

AUGUSTO, L.; SANTOS, S.; ESPÍRITO SANTO, P. M. E-Commerce: O papel principal da confiança. Revista Ibérica de Sistemas e Tecnologias de Informação, n. E34, p. 557-570, 2020.

BAGOZZI, R. P.; DHOLAKIA, U. M. Intentional social action in virtual communities. Journal of interactive marketing, v. 16, n. 2, p. 2-21, 2002.

BAI, X.; MARSDEN, J. R.; ROSS JR, W. T.; WANG, G. How e-WOM and local competition drive local retailers' decisions about daily deal offerings. Decision Support Systems, v. 101, p. 82-94, 2017. 
BERNAL, W. N.; JIMENEZ-BARROS, M. A.; MOLINARES, D. J.; PATERNINAARBOLEDA, C. D. Developing logistic software platforms: e-market place, a case study. In: International Conference on Computational Logistics. Springer, Cham, 2019. p. 380-396.

BRISLIN, R. W. Back-translation for cross-cultural research. Journal of cross-cultural psychology, v. 1, n. 3, p. 185-216, 1970.

BYRNE, B. M. Structural equation modeling with AMOS: Basic concepts, applications, and programming. New York: Routledge, 2016.

CHANG, W.-L.; YUAN, S.-T.; HSU, Carol W. Creating the experience economy in ecommerce. Communications of the ACM, v. 53, n. 7, p. 122-127, 2010.

CHEN, J.; DIBB, S. Consumer trust in the online retail context: Exploring the antecedents and consequences. Psychology; Marketing, v. 27, n. 4, p. 323-346, 2010.

CHEN, Z.; DUBINSKY, A. J. A conceptual model of perceived customer value in ecommerce: A preliminary investigation. Psychology \& Marketing, v. 20, n. 4, p. 323-347, 2003.

CHEUNG, C. M. K.; CHAN, G. W. W.; LIMAYEM, M. A critical review of online consumer behavior: Empirical research. Journal of electronic commerce in organizations (JECO), v. 3, n. 4, p. 1-19, 2005.

CHILDERS, T. L.; CARR, C. L.; PECK, J.; CARSON, S. Hedonic and utilitarian motivations for online retail shopping behavior. Journal of retailing, v. 77, n. 4, p. 511-535, 2001.

CHINOMONA, R.; MAZIRIRI, E. T. The influence of brand awareness, brand association and product quality on brand loyalty and repurchase intention: a case of male consumers for cosmetic brands in South Africa. Journal of Business and Retail Management Research, v. 12, n. 1, 2017.

CHIU, C.-M.; CHANG, C.-C.; CHENG, H.-L.; FANG, Y.-H. Determinants of customer repurchase intention in online shopping. Online Information Review, v. 33, n. 4, p. 761-784, 2009.

CHIU, C.-M.; HSU, M.-H.; LAI, H.; CHANG, C.-M. Re-examining the influence of trust on online repeat purchase intention: The moderating role of habit and its antecedents. Decision Support Systems, v. 53, n. 4, p. 835-845, 2012.

CHOU, S.-W.; HSU, C.-S. Understanding online repurchase intention: social exchange theory and shopping habit. Information Systems and e-Business Management, v. 14, n. 1, p. 1945, 2016.

DAVIS, F. D. Perceived usefulness, perceived ease of use, and user acceptance of information technology. MIS Quarterly, v. 13, n. 3, p. 319-340, 1989.

DELIBERALI, E. T.; BRANDÃO, M. M.; BIZARRIAS, F. S. Intenção de Recompra Condicionada à Confiança Econômica no Polo de Rua. Brazilian Business Review, v. 16, n. 6, p. 589-606, 2019. 
DICK, A. S.; BASU, K. Customer loyalty: toward an integrated conceptual framework. Journal of the Academy of Marketing Science, v. 22, n. 2, p. 99-113, 1994.

DING, Y.; KEH, H. T. A re-examination of service standardization versus customization from the consumer's perspective. Journal of Services Marketing, v. 30, n. 1, p. 16-28, 2016.

DUARTE, P.; E SILVA, S. C.; FERREIRA, M. B. How convenient is it? Delivering online shopping convenience to enhance customer satisfaction and encourage e-WOM. Journal of Retailing and Consumer Services, v. 44, p. 161-169, 2018.

E-BIT NIELSEN. WEBSHOPPERS. 40ª edição 2019. Disponível em: $<$ https://www.ebit.com.br/webshoppers/download?pathFile=D\%3A\%5CEbit\%5CWebsites\%5 Cwww.ebit.com.br\%5CPDF_WS\%5C40.webshoppers_2019.pdf;fileName=Webshoppers_40. pdf.>. Acesso em: 15 abr. 2020.

ELKASEH, A. M.; WONG, K. W.; FUNG, C. C. Perceived ease of use and perceived usefulness of social media for e-learning in Libyan higher education: A structural equation modeling analysis. International Journal of Information and Education Technology, v. 6, n. 3, p. 192, 2016.

ELLIOTT, M. T.; SPECK, P. S. Factors that affect attitude toward a retail web site. Journal of Marketing Theory and Practice, v. 13, n. 1, p. 40-51, 2005.

FANG, Y.; QURESHI, I.; SUN, H.; MCCOLE, P.; RAMSEY, E.; LIM, K. H. Trust, Satisfaction, and Online Repurchase Intention: The Moderating Role of Perceived Effectiveness of E-Commerce Institutional Mechanisms. MIS Quarterly, v. 38, n. 2, p. 407 427, 2014.

FORNELL, C.; LARCKER, D. F. Evaluating structural equation models with unobservable variables and measurement error. Journal of Marketing Research, v. 18, n. 1, p. 39-50, 1981.

GEFEN, D. TAM or just plain habit: A look at experienced online shoppers. Journal of Organizational and End User Computing (JOEUC), v. 15, n. 3, p. 1-13, 2003.

GEFEN, D.; STRAUB, D. W. The relative importance of perceived ease of use in IS adoption: A study of e-commerce adoption. Journal of the Association for Information Systems, v. 1, n. 1, p. 8, 2000.

GENTILE, C.; SPILLER, N.; NOCI, G. How to sustain the customer experience: An overview of experience components that co-create value with the customer. European Management Journal, v. 25, n. 5, p. 395-410, 2007.

GUO, L.; LOTZ, S. L.; TANG, C.; GRUEN, T. W. The role of perceived control in customer value cocreation and service recovery evaluation. Journal of Service Research, v. 19, n. 1, p. 39-56, 2016. 
GUPTA, S.; KIM, H.-W. The moderating effect of transaction experience on the decision calculus in on-line repurchase. International Journal of Electronic Commerce, v. 12, n. 1, p. 127-158, 2007.

HA, H.; JANDA, S.; MUTHALY, S. A new understanding of satisfaction model in e-repurchase situation. European Journal of Marketing, v. 44, n. 7/8, p. 997-1016, 2010.

HAIR, N.; ROSE, S.; CLARK, M. Using qualitative repertory grid techniques to explore perceptions of business-to-business online customer experience. Journal of Customer Behaviour, v. 8, n. 1, p. 51-65, 2009.

HEITMANN, M.; LEHMANN, D. R.; HERRMANN, A. Choice goal attainment and decision and consumption satisfaction. Journal of Marketing Research, v. 44, n. 2, p. 234-250, 2007.

HOMBURG, C.; GIERING, A. Personal characteristics as moderators of the relationship between customer satisfaction and loyalty — an empirical analysis. Psychology \& Marketing, v. 18, n. 1, p. 43-66, 2001.

HONG, I. B.; CHO, H. The impact of consumer trust on attitudinal loyalty and purchase intentions in B2C e-marketplaces: Intermediary trust vs. seller trust. International Journal of Information Management, v. 31, n. 5, p. 469-479, 2011.

HOSSAIN, M. A.; QUADDUS, M. Expectation-confirmation theory in information system research: A review and analysis. In: Information Systems Theory. Springer, New York, NY, 2012. p. 441-469.

HSU, M.-H.; CHANG, C.-M.; CHU, K.-K.; LEE, Y.-J. Determinants of repurchase intention in online group-buying: The perspectives of DeLone \& McLean IS success model and trust. Computers in Human Behavior, v. 36, p. 234-245, 2014.

HU, L.; BENTLER, P. Cutoff criteria for fit indexes in covariance structure analysis: Conventional criteria versus new alternatives. Structural Equation Modeling: a Multidisciplinary Journal, v. 6, n. 1, p. 1-55, 1999.

HUANG, W. Y.; DUBINSKY, A. J. Measuring customer pre-purchase satisfaction in a retail setting. The Service Industries Journal, v. 34, n. 3, p. 212-229, 2014.

HUBERT, M.; BLUT, M.; BROCK, C.; BACKHAUS, C.; EBERHARDT, T. Acceptance of smartphone-based mobile shopping: Mobile benefits, customer characteristics, perceived risks, and the impact of application context. Psychology \& Marketing, v. 34, n. 2, p. 175194, 2017.

HUME, M.; MORT, G. S.; WINZAR, H. Exploring repurchase intention in a performing arts context: who comes? And why do they come back? International Journal of Nonprofit and Voluntary Sector Marketing, v. 12, n. 2, p. 135-148, 2007.

KAHN, B. E. Dynamic relationships with customers: High-variety strategies. Journal of the Academy of Marketing Science, v. 26, n. 1, p. 45-53, 1998. 
KALIA, P. Who Spends the Highest Penny in Online Shopping? International Journal of EServices and Mobile Applications (IJESMA), v. 10, n. 2, p. 1-16, 2018.

KHALIFA, M.; LIU, V. Online consumer retention: contingent effects of online shopping habit and online shopping experience. European Journal of Information Systems, v. 16, n. 6, p. 780-792, 2007.

KIM, C.; GALLIERS, R. D.; SHIN, N.; RYOO, J. H.; KIM, J. Factors influencing Internet shopping value and customer repurchase intention. Electronic Commerce Research and Applications, v. 11, n. 4, p. 374-387, 2012.

KIM, H.-S.; JIN, B. Exploratory study of virtual communities of apparel retailers. Journal of Fashion Marketing and Management, v. 10, n. 1, p. 41-55, 2006.

KIM, T. T.; KIM, W. G.; KIM, H.-B. The effects of perceived justice on recovery satisfaction, trust, word-of-mouth, and revisit intention in upscale hotels. Tourism Management, v. 30, n. 1, p. 51-62, 2009.

KIM, W.; OK, C.; CANTER, D. Contingency variables for customer share of visits to fullservice restaurant. International Journal of Hospitality Management, v. 29, n. 1, p. 136$147,2010$.

KOUFARIS, M.; KAMBIL, A.; LABARBERA, P. A. Consumer behavior in web-based commerce: an empirical study. International Journal of Electronic Commerce, v. 6, n. 2, p. 115-138, 2001.

LEE, M. K.; TURBAN, E. A trust model for consumer internet shopping. International Journal of Electronic Commerce, v. 6, n. 1, p. 75-91, 2001.

LIANG, L. J.; CHOI, H. C.; JOPPE, M. Exploring the relationship between satisfaction, trust and switching intention, repurchase intention in the context of Airbnb. International Journal of Hospitality Management, v. 69, p. 41-48, 2018.

LIMA, V. Z.; MILAN, G. S.; GRACIOLA, A. P.; DE TONI, D. O comprometimento e seus efeitos sobre a satisfação de clientes, a intenção em defender a marca e a intenção de recompra em serviços de ensino. Revista Gestão Universitária na América Latina-GUAL, v. 11, n.3, p. 235-255, 2018.

MARAKANON, L.; PANJAKAJORNSAK, V. Perceived quality, perceived risk and customer trust affecting customer loyalty of environmentally friendly electronics products. Kasetsart Journal of Social Sciences, v. 38, n. 1, p. 24-30, 2017.

MITTAL, V.; KAMAKURA, W. Satisfaction, repurchase intent, and repurchase behavior: Investigating the moderating effect of customer characteristics. Journal of Marketing Research, v. 38, n. 1, p. 131-142, 2001.

MONSUWÉ, T. Y.; DELLAERT, B. G. C.; DE RUYTER, K. What drives consumers to shop online? A literature review. International Journal of Service Industry Management, v. 15, n. 1, p. 102-121, 2004. 
MORGAN, R. M.; HUNT, S. D. The commitment-trust theory of relationship marketing. Journal of Marketing, v. 58, n. 3, p. 20-38, 1994.

NDUBISI, N. O.; LEE, C. H.; EZE, U. C. Analyzing key determinants of online repurchase intentions. Asia Pacific Journal of Marketing and Logistics, 2011.

NISAR, Tahir M.; PRABHAKAR, Guru. What factors determine e-satisfaction and consumer spending in e-commerce retailing?. Journal of Retailing and Consumer Services, v. 39, p. 135-144, 2017.

OLIVER, R. L. A cognitive model of the antecedents and consequences of satisfaction decisions. Journal of Marketing Research, v. 17, n. 4, p. 460-469, 1980.

OZTURK, A. B.; BILGIHAN, A.; NUSAIR, K.; OKUMUS, F. What keeps the mobile hotel booking users loyal? Investigating the roles of self-efficacy, compatibility, perceived ease of use, and perceived convenience. International Journal of Information Management, v. 36, n. 6, p. 1350-1359, 2016.

PACHECO, N. A.; LUNARDO, R.; SANTOS, C. P. A perceived-control based model to understanding the effects of co-production on satisfaction. BAR - Brazilian Administration Review, v. 10, n. 2, p. 219-238, 2013.

PAGBRASIL (2019). Os números do comércio digital. Disponível em:

<https://www.pagbrasil.com/pt-br/insights/relatorio-digital-in-2019-brasil/>. Acesso em: 15. abr.2020.

PARK, I.; BHATNAGAR, A.; RAO, H. R. Assurance seals, on-line customer satisfaction, and repurchase intention. International Journal of Electronic Commerce, v. 14, n. 3, p. 11 $34,2010$.

PEARSON, J. M.; PEARSON, A.; GREEN, D. Determining the importance of key criteria in web usability. Management Research News, 2007.

PEE, L. G.; JIANG, J.; KLEIN, G. Signaling effect of website usability on repurchase intention. International Journal of Information Management, v. 39, p. 228-241, 2018.

PENTINA, I.; PRYBUTOK, V. R.; ZHANG, X. The role of virtual communities as shopping reference groups. Journal of Electronic Commerce Research, v. 9, n. 2, p. 114, 2008.

PEPPERS, D.; ROGERS, M. Managing Customer Experience and Relationships: A Strategic Framework. John Wiley; Sons, 2016.

PODSAKOFF, P. M.; ORGAN, D. W. Self-reports in organizational research: Problems and prospects. Journal of Management, v. 12, n. 4, p. 531-544, 1986.

QAZI, A.; TAMJIDYAMCHOLO, A.; RAJ, R. G.; HARDAKER, G.; STANDING, C. Assessing consumers' satisfaction and expectations through online opinions: Expectation and disconfirmation approach. Computers in Human Behavior, v. 75, p. 450-460, 2017. 
RAZAK, N. S. A.; MARIMUTHU, M.; OMAR, A.; MAMAT, M. Trust and repurchase intention on online tourism services among Malaysian consumers. Procedia-Social and Behavioral Sciences, v. 130, p. 577-582, 2014.

RODRÍGUEZ-TORRICO, P.; SAN-MARTÍN, S.; SAN JOSÉ-CABEZUDO, R. What drives M-shoppers to continue using mobile devices to buy? Journal of Marketing Theory and Practice, v. 27, n. 1, p. 83-102, 2019.

ROSE, S.; CLARK, M.; SAMOUEL, P.; HAIR, N. Online customer experience in e-retailing: an empirical model of antecedents and outcomes. Journal of Retailing, v. 88, n. 2, p. 308$322,2012$.

SINGH, J.; SIRDESHMUKH, D. Agency and trust mechanisms in consumer satisfaction and loyalty judgments. Journal of the Academy of marketing Science, v. 28, n. 1, p. 150-167, 2000.

SRINIVASAN, S. S.; ANDERSON, R.; PONNAVOLU, K. Customer loyalty in e-commerce: an exploration of its antecedents and consequences. Journal of Retailing, v. 78, n. 1, p. 4150, 2002.

SZYMANSKI, D. M.; HISE, R. T. E-satisfaction: an initial examination. Journal of Retailing, v. 76, n. 3, p. 309-322, 2000.

TEO, S. H. Attitudes towards Online Shopping and the Internet. Behaviour and Information Technology, v. 21, n. 4, p. 259-71, 2002.

THE EMARKETER (2019a). EMARKETER.COM. Global Ecommerce 2019. Disponível em: <https://www.emarketer.com/content/global-ecommerce-2019>. Acesso em: 15 abr.2020.

THE EMARKETER (2019b) EMARKETER.COM. Latin America Ecommerce 2019. Disponível em: < https//www.emarketer.com/content/latin-america-ecommerce-2019>. Acesso em: 15 abr.2020.

TOUFAILY, E.; RICARD, L.; PERRIEN, J. Customer loyalty to a commercial website: Descriptive meta-analysis of the empirical literature and proposal of an integrative model. Journal of Business Research, v. 66, n. 9, p. 1436-1447, 2013.

TSAI, H.-T.; HUANG, H.-C.; JAW, Y.-L; CHEN, W.-C. Why on-line customers remain with a particular e-retailer: An integrative model and empirical evidence. Psychology \& Marketing, v. 23, n. 5, p. 447-464, 2006.

UMASHANKAR, N.; BHAGWAT, Y.; KUMAR, V. Do loyal customers really pay more for services? Journal of the Academy of Marketing Science, v. 45, n. 6, p. 807-826, 2017.

URBAN, G. L.; AMYX, C.; LORENZON, A. Online trust: state of the art, new frontiers, and research potential. Journal of Interactive Marketing, v. 23, n. 2, p. 179-190, 2009.

VALLEJO, J. M.; REDONDO, Y. P.; ACERETE, A. U. The influence of EWOM characteristics on online repurchase intention. Online Information Review, v. 40, n. 7, p. 1090-1110, 2016. 
VALVI, A. C.; FRAGKOS, K. C. Critical review of the e-loyalty literature: a purchasecentred framework. Electronic Commerce Research, v. 12, n. 3, p. 331-378, 2012.

WATHIEU, L.; BRENNER, L.; CARMON, Z.; CHATTOPADHYAY, A.; WERTENBROCH, K.; DROLET, A.; GOURVILLE, J.; MUTHUKRISHNAN, A. V.; NOVEMSKY, N.; RATNER, R. K.; WU, G. Consumer control and empowerment: a primer. Marketing Letters, v. 13, n. 3, p. 297-305, 2002.

WEBRETAILER (2020). The World's World's Top Online Marketplaces 2020. Recuperado de $<$ https://www.webretailer.com/b/online-

marketplaces/\#The worlds_top_online_marketplaces>. Acesso em 30 de junho, 2020.

WEN, C.; PRYBUTOK, V. R.; XU, C. An integrated model for customer online repurchase intention. Journal of Computer Information Systems, v. 52, n. 1, p. 14-23, 2011.

WOLF, A.; ZHANG, L. The effect of customization and gender on customers' attitude. International Journal of Hospitality Management, v. 56, p. 28-32, 2016.

WOODRUFF, R. B.; CADOTTE, E. R.; JENKINS, R. L. Modeling consumer satisfaction processes using experience-based norms. Journal of Marketing Research, v. 20, n. 3, p. 296-304, 1983.

YAN, Q.; WU, S.; WANG, L.; WU, P.; CHEN, H.; WEI, G. E-WOM from e-commerce websites and social media: Which will consumers adopt? Electronic Commerce Research and Applications, v. 17, p. 62-73, 2016.

YI, Y.; LA, S. What influences the relationship between customer satisfaction and repurchase intention? Investigating the effects of adjusted expectations and customer loyalty. Psychology \& Marketing, v. 21, n. 5, p. 351-373, 2004.

YILDIZ, E. Effects of service quality on customer satisfaction, trust, customer loyalty and word of mouth: an application on cargo companies in gümüşhane. Global Journal of Economics and Business Studies, v. 6, n. 12, p. 81-88, 2017.

YOO, J.; PARK, M. The effects of e-mass customization on consumer perceived value, satisfaction, and loyalty toward luxury brands. Journal of Business Research, v. 69, n. 12, p. 5775-5784, 2016.

YOON, S.; SEO, Y.; CHOI, Y. K. E-WOM Messaging on Social Media: social ties, temporal distance, and message concreteness. Internet Research, v. 27, n. 3, p. 495-505, 2017.

YOON, S.-J. The antecedents and consequences of trust in online-purchase decisions, Journal of Interactive Marketing, v. 16, n. 2, p. 47-63, 2002.

YU, Y. T.; DEAN, A. The contribution of emotional satisfaction to consumer loyalty. International Journal of Service Industry Management, v. 12, n. 3; 4, p. 234-250, 2001. 
ZBOJA, J. J.; VOORHEES, C. M. The impact of brand trust and satisfaction on retailer repurchase intentions. Journal of Services Marketing, v. 381, p. 390, 2006.

ZHANG, Y.; FANG, Y.; WEI, K.-K.; RAMSEY, E.; MCCOLE, P.; CHEN, H. Repurchase intention in $\mathrm{B} 2 \mathrm{C}$ e-commerce - A relationship quality perspective. Information \& Management, v. 48, n. 6, p. 192-200, 2011. 